\title{
Doers of the Word? - An enquiry into the nature of action in action learning
}

John Rooke, Caroline Altounyan, Angela Young, Stephen Young.

Published As: Rooke, J., Altounyan, C., Young, A. \& Young, S. (2007)

'Doers of the word: an inquiry into the nature of action in Action

Learning,' Action Learning Research and Practice 4(2):119 - 135.

\begin{abstract}
"But be ye doers of the word, and not only hearers of it, blinding yourselves with false ideas. Because if any man is a hearer of the word and not a doer, he is like a man looking at his natural face in a glass; for after looking at himself he goes away, and in a short time he has no memory of what he was like. But he who goes on looking into the true law which makes him free, being not a hearer without memory but a doer putting it into effect, this man will have a blessing on his acts."
\end{abstract}

Letter of St James, Chapter 1 verses 22 - 25, AD 60. (Quoted in the introduction to Revans’ ABC of Action Learning 1998)

\section{Introduction}

A recent trend in public policy in many countries is the requirement for joined up thinking' and 'joined up working'. This includes partnership within and between agencies, and between agencies and their publics. For public sector managers, the implementation of such policy is often constrained by the dominant culture and style of their organisations, (see for example, Maddock and Morgan 2000). In addition (as in the UK - particularly England) frequent structural reform in the public sector can lead to high levels of uncertainty and demoralisation. Even so, public sector managers are expected to 'deliver' the new agenda, both organisationally and nationally.

In these circumstances, there has been a growth of interest in action learning as a means to bring about the organisational and individual development required for implementing such policies. Action learning, with its emphasis on solving new problems, 
implementing solutions and learning-to-learn seems to fit the zeitgeist for a time such as this.

This paper is an attempt to explore the nature and role of action in action learning, in particular, action inside the set and outside the set. It originated when we, the authors, came together to talk about and reflect upon our diverse experiences of practice as set advisers. The notion of 'action' presented a source of difficulty to all of us, yet the existing literature tended to treat it as unproblematic.

\section{Action learning}

Action learning is an approach to the development of organisations through the resolution of work-based problems. This approach relies on the collective power of individuals working together in small groups called "sets" to learn with and from each other as they wrestle with their problem. As a consequence individual development occurs as they come to understand their problem and take action in the workplace.

Whilst it originated as an approach to the development of managers, it is now being used much more widely for personal, professional and community development (see, for example, McGill \& Beaty 1995, Attwood, Pedler \& Pritchard 2003). It rejects the separation of 'knowing' and 'doing' traditionally found in programmes of education and emphasises the need to focus directly on the problems of the workplace. Learners are encouraged to ask 'insightful questions' rather than defer to the 'programmed knowledge' of textbooks and manuals. Learning thus becomes 'cradled in the task' (Revans 1998).

Action learning begins with individuals and their unique context and biography. By actively participating in the process of creating knowledge rather than digesting what others transmit, an individual moves from a position of 'having' knowledge, to one where they 
are able to create knowledge for themselves. Learning thus becomes, in Paolo Freire's term, ‘emancipatory’ (Freire 1972).

Revans himself always resists simple definitions:

"Action learning simply cannot be packaged, and the day it is accurately described in words will be the day to stop having anything to do with it. The only way to understand it more fully is to practice it...” (1984:39)

This statement is significant. Even in his writing, Revans refuses to separate the action the 'practice' - from the theory, (which, of course, is difficult to develop without defining the concept). Indeed, one of his most frequently quoted aphorisms makes this message explicit, and we quote it here with its preamble:

“By talking about things one may claim to 'know' them, but only by actually doing them can one demonstrate, alike to oneself and others, that one does, in truth, 'know' them. There can be no learning without action, and no action without learning.” (1984:51)

When questioned about the relative importance of the separate elements of the action learning process Revans was unequivocal; learning about the self, helping others and taking action in the world were all necessary, and trying to rank them was, he asserts, the equivalent of asking which is the most important side of a triangle.

This insight into the indivisibility of action and learning conforms closely to some remarks on the subject by the philosopher Wittgenstein which we explore at some length towards the end of the following section.

\section{The literature on 'action'}

Perhaps fittingly, given its genesis, research on action learning has been relatively restrained, with a recognisable community producing comprehensive texts deriving from 
personal experience and detailing empirical research (see Revans 1984, McGill and Beaty 1995, Pedler 1997a, Weinstein 1998, McGill and Brockbank 2004). We began by reviewing these key texts with a specific focus on the nature of 'action', finding that, in the main, the 'action' component of action learning is seen as unproblematic. A more systematic search of research articles, using the EBSCO (Business Source Premier) research database with keyword "Revans” from January 1990 to June 2003 was then undertaken. Smith \& O’Neil (2003) reviewed action learning literature covering publicly available journal articles for the period 1994 - 2000. This review showed that the majority of articles about action learning had a case study emphasis, these texts seemed to have little to offer to specifically help us with our questions about the role of action in action learning. To supplement our analysis, therefore, we went on to consult some classic texts in the wider literatures of education, philosophy, sociology and organizational learning.

\section{Action outside the set}

The literature contains a strong emphasis on the importance of set members taking action outside the set (Revans 1982, McGill and Beaty 1995, Pedler \& Aspinwall 1996, Pedler 1997b, Weinstein 1997). In 'The Origins and Growth of Action Learning' (1982) Revans sets up a contraposition between 'action' and 'theory' (note, not 'inaction', procrastination or reflection) and rejects the classroom teaching of management through lectures, simulations and case studies. For Revans, 'action' is activity in the real world, where mistakes matter, where individuals have to face threats and accept an element of risk.

McGill and Beaty (1995) describe the 'action' side of the action learning equation as a 'project.' They go on to say that the set member must have some motivation in relation to the project and they must be prepared to act. They comment, "If a set member has no intention to further the project, then the action learning process will be sterile.” (p24) 
The focus on real problems is developed by Krystina Weinstein, (1997) who, on interviewing over seventy action learning participants, found that the choice of project or work based task was very important to the success or otherwise of the programme. She concludes that the 'project' element of work in a set should be something:

o Important for the individual's organisation or department

o For which the individual is responsible

o Over which the individual has authority

o Ideally, that needs to be implemented by the individual

o And with their manager's and/or a senior manager's support and commitment.

Weinstein makes it clear that the process is most effective when it involves a person or group tackling an issue for which they have responsibility and the concomitant authority to take action.

\section{Action as input to the process}

However, it would be wrong to assume that action is the aim of action learning. On the contrary, it is above all a learning process, in which action is principally an input, rather than an output. Thus,the emphasis in the literature is on learning, with action considered as a facilitator (Revans 1982, Pedler \& Aspinwall 1996, McGill and Beaty 1995, Weinstein 1997).

This point can be seen in the work of Bourner and Frost (1996) who provide testimony from action learning set participants. They solicit descriptions of the outcomes of recent action learning experiences. At first sight, it is possible to assume that there was no action at all involved in their action learning sets. The accounts identify many positive outcomes - how the set became a place of safety, the importance of relationship, the support 
of the peer group. On the other hand, 'taking action' and 'encouragement and support to take action' were hardly mentioned by the respondents, in fact there is only one explicit reference - “I discovered that action learning requires action”. What seems to be really involved here, however, is a focus on outcomes within the set.

McGill and Beaty (1995) recognise that it is not necessary to focus on an issue that runs concurrently with the set, nor need the issue be a clearly defined topic for consideration. What matters is that the project is 'real and alive' (p23). Through the set process of reflection and questioning, a set member will more systematically identify the range of actions it is possible to take, including the choice of taking no action - an informed decision may be taken that 'The action is that no specific action is required”. (p167)

Revans himself stresses the moral consequences of taking action and posits that through facing the risks involved in acting in the 'real world', individuals begin to learn about their own value systems, and thus gain self-knowledge. This emphasis on values pervades much of the literature, with Pedler \& Aspinwall (1996) clearly demonstrating the link between values and the need to take action, succinctly summarising it thus:

“...doing and action confer a moral responsibility on us, that, perhaps, the possession of knowledge alone does not.” (1996:26)

\section{Knowing how and knowing that}

But what is the precise kind of learning that is involved in this process? McGill and Brockbank (2004) construct a hierarchy of reflection, suggesting that:

“ ... prepositional knowledge (knowing about) only really comes to have internalised and real meaning as knowledge when the receiving learners begin to apply that prepositional knowledge to themselves, by relating in some way to their experience .... more specifically if as a practising professional I am to bring the prepositional knowledge into a reality for me, then by immersing myself in a task that employs that 
knowledge, I will internalise it and make it have meaning when I bring it to bear with my existing knowing-in-action and emerging reflection-in-action”

This formulation is similar to the distinction originally drawn by the linguistic philosopher Gilbert Ryle (1963) between 'knowing that' and 'knowing how' and reemphasises Revans' vital theme of the indivisibility of knowledge and action. However, there is danger of confusion here, for there are not one, but two lessons that can be taken from Revans' dictum that "there can be no learning without action and no action without learning”. In order to differentiate clearly between these two insights, we will draw further on the contribution of linguistic philosophy.

Wittgenstein (1958:150) observes that, "the grammar of the word 'knows' is evidently closely related to that of 'can', 'is able to'." The nature of this relationship is that the concept 'knowledge' is logically dependent on the concept 'action':

"If one says that knowing the $\mathrm{ABC}$ is a state of mind, one is thinking of a state of a mental apparatus (perhaps of the brain) by means of which we explain the manifestations of that knowledge.” (Wittgenstein 1958:149, emphasis in original)

Thus, it only makes sense to speak of knowledge as a state of mind, when we are explaining an action: the manifestation of knowledge. To say 'I know' and not to be able to demonstrate that knowledge in some form of activity, would be to make a claim that could not be substantiated.

But Wittgenstein is here still referring to 'knowledge that'. This is a kind of knowledge that has a central position in Western culture. It is the knowledge that is taught in classrooms and lecture halls, that is the foundation of our academic system and the professions. It is abstract, generic and putatively objective. It is, in effect, 'P' - Revans' programmed learning. Nonetheless, its possessors hold high status within our society. Wittgenstein is stressing that even this kind of knowledge is inextricably tied to action. 
Inasmuch as this is the point that Revans is making (there can be no learning without action) he is part of a considerable movement in educational thinking that stresses the importance of active learning. The conception of knowledge as a state of mind appears to underlie the educational theories that Revans and others sought to challenge. A 'state of mind' conception lacks the dynamism of an 'action' conception, leading us to think of a student as a passive receptacle waiting to receive the teacher's knowledge (Freire 1972).

Among the other notable advocates of active learning in recent years have been Kölb (1984), Cowan (1998) and Bateson (1999). A key concept is that of reflection. Cowan suggests that "learners are reflecting in an educational sense, when they analyse or evaluate one or more personal experiences, and attempt to generalize from that thinking” (1998, p17). Kölb’s (1984) learning cycle is a particularly well known formulation of this process, in which abstract conceptualisation is said to lead to active experimentation, from which derives concrete experience which provides a basis for reflective observation and in turn leads back to abstract conceptualisation. While active learning is clearly an advance on earlier conceptions of learning that assumed student passivity, it is notable that the role of action tends to be relegated, as in Kölb's model to a more or less supporting role in the development of abstract thought. This captures only a part of the meaning that action learning had for Revans.

Ryle and Wittgenstein are also making a further point, however: that it is often the case that a claim to knowledge refers in practice only to an ability and not to any state of mind:

"Let us imagine the following example: A writes a series of numbers down; B watches him and tries to find a law for the sequence of numbers. If he succeeds he exclaims: 'Now I can go on!' - So this capacity, this understanding, is something that makes its appearance in a moment.” (Wittgenstein 1958:151) 
In as much as it is this kind of knowledge with which Revans is concerned (there is no action without learning) his thinking is more aligned with that of action theorists such as Whyte (1991) or Shön (1991), or with management thinkers such as Deming (1986).

In sum then, the literature, provides us with three important distinctions with which we can analyse our experience of the action learning sets: (1) action can take place outside the set or within it; (2) it can be an input to or an output of the learning process; (3) some forms of knowledge can be regarded as a static object, a 'knowledge that', while others can only be considered as a practice, 'a knowing how'. These distinctions played a crucial role in helping us to understand and describe the variety of actions which we identified in our action learning sets.

\section{Our question}

In the light of these (and many more) comments from the founder of action learning, we might be seen as arrogant, or merely foolish, in our attempt to separate out the 'action' element for further study. Our defence is that 'action' in sets has, at times, become an issue for us. Wishing to explore the issue, we met a number of times (as a researching action learning set) over a period of twelve months.

In our own 'research' action learning set, we became aware that we might be unthinkingly 'projecting our meanings' onto the set, choosing action as a point of focus, and perhaps unbalancing the delicate learning equation that action learning establishes. We reflected on our collective choice of 'action' as an implicit measurement of success and point of focus. Was it because it is a more tangible outcome than 'learning' and can thus be included as a benefit in the inevitable evaluation of such projects? Or because, 
from a base in higher education working with practitioners, learning became an undervalued 'taken-for-granted'? Perhaps our anxieties as relatively new set advisers meant that we were unable to tolerate easily the lulls and self questioning that seem to be necessary before clarity of purpose emerges? In the busy world of work it may be that the ability to stop 'taking action' - to moderate managers' “disabling predisposition [to take] spontaneous action” (Revans 1980, p255), thus allowing space for issues of purpose and value and of alternative ways of operating - was more important than we had recognised?

We explore these questions more fully below, in an analysis of our experiences in a range of action learning sets.

\section{The Context}

Our focus is on three recent experiences of set advising, all linked by the overall aim of building capacity to tackle complex and intractable issues - social exclusion, poverty and poor health. The projects were:
a) The community strategy project
b) The project to reduce health inequalities
c) The social entrepreneur project

Action learning was chosen as the main approach in all these projects because it has been found to be particularly beneficial in situations where individuals are working on the boundaries of existing knowledge, where new ways of working are required, and where there is a need for the development of cross disciplinary interaction and relationships. Furthermore, with its focus on current and 'real' practitioner issues, and on the process of 
sharing and creating meaning it helps build a sustainable capacity to learn. All three projects were aiming to make a contribution to tackling deeply rooted problems in society. All three involved diverse groups of people, from different discipline, organisational and social backgrounds meeting together with an expectation that they would learn through taking action.

\section{(a) The Community Strategy Project}

This project took place in a local community in a city that is tackling challenges of urban deprivation and crime by working in partnership with local people through its Community Strategy. In the strategy, the city is divided into a number of different areas, each with its own Community Committee. Each committee is made up of representatives from councillors, council officers, the local community and other public service bodies. Its key activities include: developing Community Action Plans, taking decisions about delegated budgets, monitoring local authority performance, and addressing issues of importance to the local community, including concerns about crime and disorder.

The community strategy thus superimposes a horizontal, geographically based structure upon the hierarchical 'directorate' structure of the local authority. To ensure that the two structures work in harmony, the departmental post of 'Partnership Officer' was created. Partnership Officers are principal officers of council departments who are allocated the role - to provide liaison and support to specific community committees - in addition to their departmental responsibilities. There does not appear to be any inherent connection between the officer and their allocated community committee, either in terms of place of residence or duties of their substantive post. No additional payment is made for undertaking this role.

A review of the Community Strategy identified the need for greater clarity for directorates and their Partnership Officers about their roles, responsibilities and support needs. In 
response to this, the local co-ordinator for one of the communities (who had had some previous experience of action learning) approached two of the authors of this paper (CA and SY) and asked for help. It was believed that action learning would be an appropriate approach to help Partnership Officers in the area share and create knowledge about their role. Through meeting in an action learning set it was hoped to provide participants with the challenge and support they needed to fulfil the requirements of the Partnership Officer role, whilst also encouraging a more sustained approach to learning across participating individuals and organisations. A set of five volunteers from the local authority and the local police force agreed to meet for one morning a month over a period of twelve months. As part of the formal evaluation of the project, each participant took part in an hour-long, semi-structured interview with the set adviser (CA).

\section{(b) The Health Inequalities Project}

This project set out to help statutory organisations increase their capacity to tackle health inequalities. It was funded by the NHS region and aimed to build the capacity of six health authorities and their partners to tackle the issues of equity strategy, partnership working and knowledge handling. The main method chosen for this work was action learning.

The project's six sites included countryside, towns and cities, and their populations covered the spectrum from highly disadvantaged to very affluent. There was one learning set for each site with membership of the action learning sets drawn mainly from local authorities, health organisations (which included health authorities, primary care trusts and hospital trusts) and the voluntary sector. The original 'sponsor' of the action learning set in each site was the Director of Public Health at the health authority - that person publicised the learning set idea, had local discussions to assess potential support and liaised with the project until the learning set was established. One site commissioned 
an additional learning set (running concurrently) so the project ran a total of seven sets. The action learning sets decided their own focus for action, usually at the first meeting. The period over which they met averaged just under a year.

Many of the set meetings were tape recorded (with members' agreement) and transcribed. After the sets had finished, participants were sent an evaluation questionnaire. The material from the project presented in this paper draws on both the transcripts and the evaluation responses. Two of the authors (CA and AY) were part of the team of three set advisers for the project. A third author (JR) organised the transcripts and conducted the initial analyses.

\section{(c) The Social Entrepreneur Project}

The School for Social Entrepreneurs (SSE) is a national programme, founded in 1997 by Michael Young (Lord Young of Darlington). Its purpose is to provide training and opportunities to enable people to use their creative and entrepreneurial activities for the benefit of their local community. In adopting an action learning approach the School believes that:

\footnotetext{
"Entrepreneurs prefer action to reflection: they want to get on with it. They are willing to explore their environment for opportunities and resources, and to take risks. They are "people" people. They aren't interested in learning programmes that don't seem relevant to them, and they often move straight into action without any educational preparation. They learn as they go.” (SSE 2003)
}

The first local SSE programme that was built on the national programme was run in a large northern town. Five grass roots activists from differing communities in the town were recruited, and as a major component of the programme they formed an action learning set, advised by one of the authors of this paper (SY). The set commenced in November 1999 and members met monthly over the following twelve months. An independent evaluation of the SSE programme found that: "action learning remained as one of the Rooke, Altounyan, Young, Young 2007: Doers of the Word. 
most valued parts of the SSE programme for all the participants: the concept of action learning is superb” (SSE 2000, p44).

\section{An analysis of action in the action learning sets}

In line with Revans' writings, members of the action learning sets were encouraged to focus on problems and issues that they were facing within their work, rather than create a separate and specific 'project' to address. Revans wrote that significant learning comes from taking action on issues that really matter to the individual and which are crucial to their future success. He believed that only by identifying and tackling such issues would the motivation to continue through the difficult times be found.

So, at the outset of the three projects, there was an explicit expectation on the part of ourselves as set advisers, (and, presumably, given the way we had described action learning in our proposals, our sponsors) that action would be taken 'on the ground' to tackle 'real problems'. Indeed, this expectation was built in to the evaluation processes we adopted. The health inequalities project's questionnaire asked 'What do you feel were the outcomes of your learning set?' and meetings transcripts were analysed for instances of 'actions taken' during the life of the project. Participants in the community strategy set were asked 'What action did you take as a result of being in the set?' Social entrepreneurs were similarly asked "What have you achieved during the project?" In addition to this, it is our practice as set advisers to conclude each set meeting with a question about 'points to be actioned' before the next meeting, and to open up the subsequent meeting with some discussion on these points. Thus there is a continuous process of monitoring of action.

Through discussing our own experience as set advisers and by analysing the activities of learning set members, we gradually advanced our understanding of action and the role it plays in action learning. We learned to identify actions taken within the set and distin- 
guish them from those taken outside it. While it is the relevance of action to 'the real world out there' that gives it its potency as a stimulus to learning, we realised that the relationship between 'inside' and 'outside' the set was more subtle than it first appeared. Set members may be reflecting on action taken outside, or preparing for it, or they may simply be expressing frustration generated by their real world situation. An important turning point occurred when we clearly understood that action is not the goal, but the means by which learning is achieved. Another was when we realised that much of the knowledge acquired was of types that are usually undervalued in educational establishments, whether because it is not generic (knowledge of local networks) or because it what we have termed 'knowledge as practice'. We also recognised that knowledge is not simply an individual possession, but is acquired, held and manifested by groups of people working in concert with each other.

In the light of these insights and drawing on our literature review we recognised the following three distinctions to create the typology below. First, drawing on the work of linguistic philosophers, but also on Revans' own formulation: the processes that occur within the action learning sets are considered as actions in themselves. Thus, the five types are arranged on a continuum: from expressive action within the set; through the enrichment of knowledge and networks, changes in personal practice, and collective action, in which the focus progressively shifts to activities outside the set; to organizational change, which occurs principally outside the set.

Second, drawing specifically on the action learning literature, these actions are considered as both inputs to and outputs from the learning process. Again, the five types follow a continuum, from expressive action, which may be considered as entirely an input to the process, through the other types, to organizational change, which is principally (though not exclusively) an output. 
Finally, the enrichment of knowledge and networks is largely a process of gaining 'knowledge that', while the other types are concerned with 'knowing how'.

\section{i) Action inside the set}

\section{(a) Expressive action - pointless talk?}

The first type of action we identify takes place inside the set. We call it expressive action after Parsons' (1968) distinction between this and means-ends oriented action. Expressive action is action for its own sake. Thus, it is not oriented towards either a learning objective, or an organisational objective. As a consequence, its importance tends to be underplayed in a culture that places a high value on achievement and despite Parsons' powerful synthesis of the work of several nineteenth and twentieth century thinkers who have highlighted the importance of expressive action, it is still often overlooked. Much of the action that took place in our sets belonged in this category and, in our view, was integral to the learning process. For example, in the words of one participant, the learning set provided: “a place you can let off steam in a safe environment” (SSE 2000).

There is, of course, a danger in expressive action: if the set consists entirely of such activity, it will not be productive. One participant complained of a learning set he had attended (not one of ours!) that deteriorated into a mere "moaning shop”. However, as another participant came to realise, expressive activity can be a vital preparation for other things.

Initially, this set member found the action learning set meetings:

"Extremely tiresome and felt that I was gaining very little from the time I was investing in them ... People were discussing their children, their own environments, their love lives and even what was in the oven for tea.” (SSE 2000)

With further reflection and experience of the set she soon began to realize; 
"What I considered chit chat [in the set] was in fact group building, and that all the set members needed to be where they were at that time in order to become comfortable and trusting with each other. I also realised that if there are any issues that I would like to discuss then I would have to bring them to the set and not expect other people in the set to know what my needs are. Two very valuable learning experiences.” (SSE 2000)

These learning experiences imply both changes in personal practice and the development of collective action, both of which are discussed in more detail below. Expressive action, then, is an important input to the process, though the output it generates is therapeutic and preparatory, rather than being a learning experience in its own right.

\section{(b) Learning as action - enriching knowledge and networks}

In the process of action learning the starting point is one that is rooted in "ignorance" (no knowledge) where the practitioner has no known solution to a work based problem. Action learning therefore allows us to discover what it is we do not know.

It is now well established in educational theory that people learn better through activity and experience than when they are treated as passive receptacles for knowledge (Freire 1972, Kolb 1984). Action learning is active learning par excellence - while other approaches attempt to bring activity into the classroom, action learning turns the whole organisation and work setting into a huge classroom for learning set participants. This is the case even when the type of learning that takes place is conventional in nature (i.e. McGill \& Brockbank's prepositional knowledge, or Ryle's 'knowing that'; knowledge that can be readily conceived of as an object, rather than a practice). We have identified two kinds of object knowledge: generic knowledge: and local organisational knowledge.

By generic knowledge, we mean the kind of knowledge that is usually taught in a classroom, or can be garnered from a textbook. As an example of the former, some of the 
inequalities sets decided that it would be useful to them to invite an academic speaker to explain various technical issues.

Our term 'local organisational knowledge' refers to a number of kinds of knowledge acquired in the sets, which lie outside the usual scope of academic activity, such as finding out who's who in the local organisational context, or finding out what data is available, on which data-bases and how easily it can be accessed. One participant in the SSE set observed:

"Through the set I believe we have created a lot of common knowledge about our roles, we have increased our knowledge base.” (SSE 2000)

Another remarked:

"The action learning set made me look at the wider picture around my project." (SSE 2000)

Both types of knowledge are vital outputs of the action learning process. These types of knowledge are conventionally abstracted from action in educational thinking, however: they are best acquired through active learning; they can only be demonstrated through action; and they only acquire "real meaning” through action (McGill \& Brockbank 2004). Therefore, action is an important input to the acquisition of such knowledge. While this input is usually seen by educators as some kind of classroom activity, in action learning it is more likely to take the form of information, experience and opinion exchanged in discussion among set members, and the thinking that this inspires. As another SSE participant stated:

"These are the one opportunity per month which allows us to share in the work we are doing and share ideas, experiences, etc.” (SSE 2000) 


\section{ii) Action outside the set}

\section{(c) Action as learning - changing personal practice}

This type of action illustrates 'knowledge as practice'. The orientation of conventional active learning theory is apparent in Marton, Dall'Alba \& Beatty's (1993) classification of students' conceptions of learning. Here, applied knowledge is recognised only in terms of the acquisition of facts and procedures for application and regarded as an unreflective mode of 'surface' learning. Modes of learning recognised as reflective tend, with the interesting exception of 'developing as a person', to be academic and abstract.

Revans' conception of action as learning is more akin to the notion of reflective action that can be found in the work of Freire (1972) and Shön (1991). For Freire, a concern with the emancipation of the politically oppressed led him to draw upon Marx's concept of revolutionary praxis, in which practice and theory are mutually bound together in a process that is at one and the same time action and learning. In sharp contrast, Shön 's concern is with professional practice, but his concept of reflective action parallels Freire's. What unites both these views is the equation of action and knowledge. In both cases, action takes place in the world at large, rather than in a safe educational or experimental environment. In both cases, it is not merely a useful adjunct to the learning process, but the central core of that process.

This has major implications. First, learning is appropriate to the learners' actual situation. Second, action is a product of the learning cycle, rather than a stage in the development of abstract theoretical knowledge. Knowledge is thus practical and experientially tested, as opposed to abstract and theoretical. This, the kind of knowledge Ryle (1963) calls 'knowing how', is difficult, perhaps impossible to objectify as descriptions and consequently to convey through the active teacher/passive student model of learning. This is practical knowledge: skills or abilities. It is typically learned through 
reflective practice. Teachers may act as instructors, or guides, but the learning process always centres on the student's own practice. Paul Griseri (2002) argues that as management is an applied practice, any distinction between knowledge and action is artificial; rather they are two different elements of a single process. He defines 'action' as intentional behaviour and includes practices and strategies as well as choices and decisions.

It should be remembered, however, that even in this conception of reflective action, for most people, especially in large organisations, action still consists in talk, or at least communication. It is crucial to note that talk does not only consist in 'talking about things'. The great majority of the consequence laden activities which we undertake are performed wholly or partly through communication of one kind or another, for example, giving an order, making a request, or taking a position (Wittgenstein 1958, Winch 1990).

Revans himself stresses this subtle yet important distinction:

“...confusion tends to arise because so much managerial action is necessarily an exchange of words that the distinctions between getting something done and talking about getting it done may be simply overlooked.” (1998, p7)

The learning set functions by acting as an environment in which participants can reflect on their activities, whether those take place in the set or outside it. Thus, action within the set becomes an object of attention for both self and others, setting up a reflective relationship in which activity is examined to reveal its significance from different points of view. For instance, one set member observed:

"I found it difficult to answer questions about abstract, conceptual things, I realised that I don't have an opinion on these things, and therefore, whilst I could provide a glib answer, I would rather say nothing than risk being untruthful.” (Interview with community strategy set member)

The set advisor observed in her notes: 
“When I tried to challenge him on issues, he says 'I don't have an answer to that question', which is rather frustrating - I remember that last meeting I did try to push him on this by saying 'try'. But very little results in terms of insight probably his long training as a politician - not showing any vulnerability or weakness.”

Action, in the form of changed practice, is the key output of this kind of learning. Set members gave testimony to the many ways in which practice can be changed.

"I now think more about what information I get from external sources and how I feed that back into my own organisation, I ensure that wherever possible information is available for everyone to use rather than keeping it to myself." (Participant in the community strategy set).

"I have learnt to be more self-confident and have used this to pursue what I want to do, rather than be influenced by other people's agendas. This has helped me to be honest about my relationship with others.” (Participant in the SSE set).

\section{(d) Collective Action - sharing knowledge and acting together}

Changes in personal practice do not necessarily imply organisational change. As one community strategy set member observed:

“I don’t do my Partnership Officer job any differently as a result of the set - you can’t do 'nothing' differently” (interview with community strategy set member).

This is because collective action is necessary to get anything done in an organisation. Thus, individual actions can only be effective in as much as they elicit an appropriate response from others. Sometimes action learning sets take collective action; at other times, individuals use the set to discuss collective actions they are taking, or attempting to initiate elsewhere.

The neglect of collective action is one danger for action learning sets. As the participant quoted above remarked: 
“A project would have given us more focus - if we'd owned up earlier that we had no Partnership Officer business to share, we could have moved to the 'project' quicker.” (ibid)

The collective nature of organisational action can be overlooked. In the social entrepreneurs set, participants perceived in the programme an overemphasis on personal development and an imbalance against project development. As one observed, "it is through doing the work on the project that many of the learning experiences come” (SSE 2000).

Where the organisational context is difficult, a set project can provide a meaningful focus:

"I enjoyed doing the report, I felt I was making a contribution to the group, there was a tremendous feeling of playing a real part in something." (Interview with community strategy set member).

Under more favourable conditions, the sets had real organisational consequences. Two of the 'tackling health inequalities' sets were particularly successful in this regard. One became the nucleus for a rural inequalities network, another the focus for building a strategic relationship between the NHS and a local authority.

\section{(e) Organisational learning - improvement and change}

Organisational change (improvement) is the outcome of effective collective action. Organisational change, or more specifically organisational improvement, was an intended outcome of all the sets. In no case was this unambiguously achieved. It is the attempt to achieve this level of action that generates much of the frustration that is expressed by action learning set participants. It requires a lot more than the members of a single learning set can do alone. As Revans warns, nothing will change "unless the management at all levels is part of the scheme marketed as action learning” (1998 p72). Griseri (2002) suggests that management research (and here we could include the 
learning that takes place in a set) cannot be fully meaningful unless the organisation can digest its outcomes, and by 'digesting' he means turning the outcomes into potential action. So if the learning that is created in an action learning set is in some way challenging to the organisation, i.e. difficult to digest, then it is unlikely that any action in the sense of significant and intentional change will ensue.

The Community Strategy project and the Tackling Health Inequalities project were designed to 'build capacity' in their participants. In neither proposal document was there an explicit requirement for people to bring to the set accounts of the problems they were concerned about and that they had a pressing and personal need to tackle. Discussions with the sponsors of the Community Strategy project had suggested that there were very real problems being faced by prospective participants and that the action learning set would provide a forum for helping individuals to tackle such problems. The participants themselves, however, failed to recognise any such 'problems', so that whilst they were aware of the challenges facing the council as it strived to implement its community strategy, they did not regard these challenges as their problem. Thus, they were unable to bring to the set, in Revans’ words: “a responsible and real assignment which would carry penalties for failure”. This was recognised fairly early on in set meetings, and as noted above set members did cast around for a 'project' to work on and this had some effect:

\footnotetext{
"We needed burning issues to talk about, to give us things to focus on, but we didn't have them ... we didn't have a specific job to do ... through the set we chose to do things - I think I have done more as a Partnership Officer through being in the set than I have in the previous two years." (Interview with community strategy set member).
}

However, as the community issue that the set was addressing formed only a small fraction of the role of the set members, attempts to instigate new work that might be useful were unsuccessful: 
"I can see that you could throw yourself wholeheartedly into it, and get involved in all sorts of interesting things, but in practical terms, with the heavy workloads we are all carrying, the view is - go along to meetings if you have to, and in general act as a conduit." (Interview with community strategy set member).

\section{Conclusion}

We conclude that the key to evaluating the performance of action learning sets is the clear recognition that the importance of action is as a motivator of learning, an input to the educational process. Seen in this light, activities such as 'letting off steam', 'getting to know people' and reflecting on vicissitudes of the daily grind can be seen as actions in themselves and important early stages in the process. As confidence and solidarity build among the set members, the set can be expected to become more reflective, orienting more constructively towards the outside world. This orientation can often take the form of exchanging 'local knowledge', the kind of information that has little recognised value in academic circles, but is an essential aid to practical action in any particular environment. Since such knowledge differs from setting to setting, it can never be the subject of programmed learning.

Moving along the continuum, a form of action outside the set that may be said to be identical to learning is a change in personal practice. Here, we can begin to treat action as a learning output as well as an input to the process. Whether it is a change in attitude or acquisition of a new skill or strategy, this is another form of learning that is often overlooked in conventional educational settings. An important aspect of personal practice which may be developed through action learning is the ability to work with others. Collective action is seen as an intermediate category between personal practice and organizational change. Here, the collective nature of knowledge is realised and we can begin to speak, not just of individual, but of organisational learning. Organizational change can be seen as the big prize and with proper institutional support is an achievable 
and legitimate learning outcome. Where such support is not forthcoming the outcomes will be less dramatic, though as we have argued above, nonetheless worthwhile.

7253 words

\section{References}

Attwood, M., Pedler, M. \& Pritchard, S. (2003) Leading Change: A guide to whole systems working, Bristol, Policy Press.

Bateson, G. (1999) Steps to an Ecology of Mind, Collected Essays in Anthropology, Psychiatry, Evolution, and Epistemology, Illinois, University of Chicago Press,

Bourner, T. \& Frost, P. (1996) In their own words: the experience of action learning in higher education Education + Training 38 (8) pp16-21

Cowan, J. (1998) On Becoming an Innovative University Teacher; Reflection in Action, The Society for Research into Higher Education \& Open University Press.

Deming, W. E. (1986) Out of the Crisis: Quality, productivity and competitive position, Cambridge, Cambridge University Press.

Freire, P. (1972) The Pedagogy of the Oppressed, Harmondsworth, Penguin.

Griseri, P. (2002) Management Knowledge: A Critical View, Basingstoke, Palgrave.

Kölb, D. A. (1984) Experiential Learning: Experience as the source of learning and development, London, Prentice-Hall.

Maddock S. \& Morgan G. (2000) Conditions for Partnership, Manchester Business School. Web page accessed 18/12/03, http://www.mbs.ac.uk/research/nwcc

Marton, F., Dall’Alba, G. \& Beaty, E. (1993) 'Conceptions of Learning', in International Journal of Educational Research, 19(3) pp277-300.

McGill, I., \& Beaty, L. (1995) Action Learning: A Guide for Professional, Managerial and Educational Development (second edition) London, Kogan Page.

McGill, I., \& Brockbank, A. (2004) The Action Learning Handbook, London, Routledge Falmer.

Parsons, T. (1968) The Structure of Social Action (second edition: two volumes) London, Collier Macmillan.

Pedler, M. (ed) (1997a) Action Learning in Practice (third edition), Aldershot, Gower.

Pedler, M. (1997b) ‘Interpreting Action Learning’, in J. Burgoyne \& M. Reynolds (eds.) Management Learning, London, Sage.

Pedler, M. \& Aspinwall, K. (1996) Perfect PLC? The purpose and practice of 
organisational learning, Maidenhead, McGraw Hill.

Revans R. W. (1980) Action Learning: new techniques, London, Bland \& Briggs.

Revans R. W. (1982) The Origins and Growth of Action Learning, Kent, Chartwell-Bratt Ltd.

Revans R. W. (1984) The Sequence of Managerial Achievement, Bradford, MCB University Press.

Revans, R. W. (1998) The ABC of Action Learning, London, Lemos \& Crane.

Ryle, G. (1963) The Concept of Mind, Harmondsworth, Penguin.

Shön, D. A. (1991) The Reflective Practitioner: How Professionals Think in Action, Aldershot, Arena.

Smith, P. A. C. \& O’Neil, J. (2003) 'A Review of Action Learning Literature 1994 2000’, Journal of Workplace Learning, 15(2) pp63-69.

SSE (2000) Taking the Risk to Blossom, Salford Social Entrepreneurs Programme Report on the pilot programme 1999 - 2000, London: School for Social Entrepreneurs, and Eccles: Salford Community Health Council.

SSE (2003) Learning Through Action: Why action learning? Web page accessed 4/12/03, http://www.sse.org.uk/network/learning/why action learning.shtml

Weinstein, K. (1997) Participants' Voices in Pedler MJ (ed) Action Learning in Practice (third edition), Aldershot, Gower.

Weinstein, K. (1998) Action Learning A Practical Guide, Aldershot, Gower.

Whyte, W. F. (1991) Social Theory for Action, London, Sage.

Winch, P. (1990) The Idea of a Social Science and its Relation to Philosophy (second edition) London, Routledge and Kegan Paul.

Wittgenstein, L. (1958) Philosophical Investigations (second edition) Oxford, Blackwell. 